\title{
Synchronous and Asynchronous Discussions: Effects on Cooperation, Belonging, and Affect
}

\author{
Amy T. Peterson, Patrick N. Beymer, and Ralph T. Putnam \\ Michigan State University
}

\begin{abstract}
Supporting productive peer-to-peer interaction is a central challenge in online courses. Although cooperative learning is a well-established method for eliciting productive interaction (Johnson \& Johnson, 1989), online modes of cooperative learning have provided mixed results. To explore the factors underlying these mixed results, we used a quasi-experimental design to examine the effects of synchrony on students' sense of cooperation, belonging, affect, and cognitive processes in online small-group, discussion-based cooperative learning. Fifty-two undergraduate students were assigned to synchronous and asynchronous interaction conditions in an online course. The findings support prior research that asynchronous communication interferes with the relationship between cooperative goals and the outcomes of cooperation. The results extend the literature by indicating that synchrony positively affects students' perceptions of belonging, positive affect, and cognitive processes. Results inform theory and practice by showing that asynchronous cooperative learning may not work as designed due to students' lack of perceptions of interdependence.
\end{abstract}

Keywords: cooperative learning, collaborative learning, asynchronous discussion, synchronous discussion, small group

Peterson, A.T., Beymer, P.N., \& Putnam, R.T. (2018). Synchronous and asynchronous discussions: Effects on cooperation, belonging, and affect. Online Learning, 22(4), 7-25. doi:10.24059/olj.v22i4.1517

\section{Synchronous and Asynchronous Discussions: Effects on Cooperation, Belonging, and Affect}

Supporting productive peer-to-peer interaction is a central challenge in online courses. This study examines cooperative learning as a method for supporting interaction. Although cooperative learning research provides robust evidence for the positive outcomes of face-to-face cooperative learning (Johnson \& Johnson, 1989), online modes of cooperative learning have provided mixed results. Online learning is often synonymous with asynchronous interaction. The increasing use of synchronous formats, however, has resulted in multiple technologies to facilitate students' interactions and expanded the modes of interaction available to students; online cooperative learning is no longer solely asynchronous (Jeong \& Hmelo-Silver, 2012, 2016). Thus, 
existing research on online cooperative learning may not reflect how educators and students are using communication technologies.

This study examines the effects of synchronous versus asynchronous cooperative learning on students' sense of cooperation, belonging, and affect in online small-group cooperative discussions. The purpose of the study was to identify effects of asynchronous communication on cooperative learning. In the literature review, we place cooperative learning within the context of collaborative learning, explain the gaps in asynchronous cooperative learning literature, and describe the research questions. We then describe the design of the course we studied, the measures used, and our methods of analysis. In the final sections, we discuss results, limitations, and implications.

\section{Theoretical Framework}

In collaborative learning, students work together to negotiate and create shared group meaning (Stahl, Koschmann \& Suthers, 2014). Cooperative learning, a more structured form of collaborative learning, is designed to promote the interdependence of students. According to social interdependence theory, the structure of interactions affects participants' affective and motivational states, such as belonging, affect, trust, and performance (Deutsch, 1949; Johnson \& Johnson, 1989, 2005). In positive social interdependence (cooperation), participants have positive feelings about the activities and those with whom they have cooperated. When participants interact effectively with positive interdependence, they communicate effectively, coordinate their efforts, and share similar beliefs and values with other group members (Deutsch, 2012). In negative social interdependence (competition), participants adopt negative attitudes toward one another and have difficulty effectively coordinating their efforts. In small-group work, cooperative goals, in which one person's goal attainment is linked with another person's, are central to positive interdependence.

\section{Asynchronous Cooperation}

When researchers (Peterson \& Roseth, 2016; Roseth, Saltarelli, \& Glass, 2011; Saltarelli \& Roseth, 2014) have compared synchronous and asynchronous communication in cooperative online learning, they found that asynchronous communication does not always support cooperative learning processes. For example, Roseth, Saltarelli, and Glass (2011) compared synchronous and asynchronous cooperative activities in video, audio, and text modes. Although the medium did not play a role in students' motivation or academic achievement, synchrony affects students' perceptions of cooperation. Saltarelli and Roseth (2014) examined the additive effects of synchrony and belonging on cooperative perceptions and found that belonging buffers some of the negative effects of asynchrony on cooperation. These two studies were limited in the sense that participants were recruited from on-campus courses and therefore, may not necessarily be accustomed to online learning. The current study addresses this limitation by testing a series of cooperative learning activities in an actual online course.

Each of these studies found that positive goal interdependence in the design of cooperative learning activities does not predict positive social interdependence in asynchronous contexts as it does in face-to-face (FTF) contexts. Therefore, there is a need to explore how synchrony affects cooperative learning. The first research question this study explores is whether cooperative perceptions are achieved similarly in synchronous and asynchronous modes. 


\section{Cooperative Learning Outcomes: Belonging and Affect}

The second focus of this study is on cooperative outcomes of belonging and affect (positive and negative). Positive interdependence leads to a great sense of belonging (Johnson \& Johnson, 1989 ) in cooperative learning. Belongingness refers to frequent, positive interaction with others that occurs within an ongoing relationship of mutual caring (Baumeister \& Leary, 1995). Cooperation is driven, in part, by an individual's need to belong, and thereby leads to a higher sense of belonging than competition and individualism (Johnson \& Johnson, 1989). Even when participants view others as being outside their group, those in cooperative situations view others more positively than those in competitive or individualistic situations (Worchel, Axsom, Ferris, Samaha, \& Schweizer, 1978). When viewed through the lens of student engagement, belonging contributes to students' social-behavioral engagement, which refers to emotional engagement in specific learning tasks such as peer interaction (Pekrun \& Linnenbrink-Garcia, 2012). Saltarelli and Roseth (2014) found that belonging could ameliorate some of the negative effects of asynchrony. Because they manipulated belonging in their study, it is unclear how belonging naturally develops in online cooperation. Additional clues to the role of belonging in online cooperation lie in social presence literature.

Social presence, the perception of "realness" of someone in online communication (Gunawardena, 1995), is related to belonging in that it can contribute to the ongoing relationship among students. In a recent review of collaborative learning, Cherney, Fetherston, and Johnsen (2017) found that technologies that afford more cues (e.g., video, audio, synchrony) are associated with greater social presence. Further evidence is needed to understand how belonging relates to online cooperation. Our second research question asks whether synchrony affects belonging in cooperative learning, which we investigate by analyzing students' self-report measures.

Emotion is defined as a short-term, specific feeling (Schunk, Meece, \& Pintrich, 2014) and may be positive (e.g., enthusiastic, happy) or negative (e.g., anxious, frustrated). Cooperation generally elicits positive emotions and inhibits negative emotions (Zschocke, Wosnitza, \& Bürger, 2015). Do these emotions occur in online interaction? Meyer and Jones (2012) found that online student presented emotions and interpreted the emotions of others in an effective way. Although students can express and interpret emotions in asynchronous and text-based environments, it is unclear whether asynchronous cooperation elicits the positive emotions that it does in face-to-face environments. Our third research question focuses on the association between synchrony and emotions in cooperative learning. We answer this research question by analyzing a self-report measure and chat logs in an online course.

\section{Cognitive Processes in Asynchronous Cooperation}

Our final focus of this study is to explore how cognitive processes might differ in synchronous and asynchronous cooperation. Cooperative learning encourages cooperative processing and enhances the incorporation of other's ideas and reasoning into one's thinking (Johnson \& Johnson, 1989). Although cooperative learning literature provides strong evidence for its ability to stimulate cognitive processing, it is unclear whether these effects occur consistently in asynchronous cooperative learning.

In his examination of asynchronous discussions, Waters (2012) found that students could emerge as thought leaders, helping stimulate conversation and interaction with others. Those who were rated as thought leaders by their peers posted more frequently and visited the discussions more frequently than those who were not rated as thought leaders. His findings suggest that activity 
in the discussion, regardless of whether it is synchronous or asynchronous, can elicit rich discussion and deep cognitive processing.

Although cognitive processing may have the potential to reach similar levels in synchronous and asynchronous conditions, the processes used in each condition may be different. For example, Wicks et al. (2015) compared high-collaboration and low-collaboration groups. The high-collaboration group worked synchronously and the low-collaboration group worked asynchronously. They found more forethought and planning in synchronous groups and more reflection in the asynchronous groups. These mixed results inform our fourth research question: do students engage in similar cognitive processes in both synchronous and asynchronous cooperation? To explore this question, we analyzed the chat logs in an online course.

Clarifying the way asynchrony affects online cooperation is important to help instructors design learning activities that achieve the desired outcomes. This study clarifies those effects by exploring four research questions in a mixed methods study. The first research question (synchrony's effect on cooperation) builds on previous research showing that asynchronous cooperation changes students' perceptions of social interdependence, diminishes cooperative perceptions and increases competitive and individualistic perceptions (Peterson \& Roseth, 2016; Roseth et al., 2011; Saltarelli \& Roseth, 2014) and extends the generalizability of the previous research. The second research question (synchrony's effect on belonging) builds on previous research showing that belonging can buffer some of the effects of asynchrony on cooperation (Saltarelli \& Roseth, 2014) and that rich technology can support social presence (Cherney, Fetherston, \& Johnsen, 2017). The third research question (synchrony's effect on emotion) follows from previous research showing that students can effectively express and interpret emotions online (Meyer \& Jones, 2012), but it is unclear whether online cooperation elicits positive emotions and inhibits negative emotions (Zschocke, Wosnitza, \& Bürger, 2015). The fourth research question (synchrony's effect on cognitive processes) follows from previous research that indicates that students engage in different cognitive processes when cooperating asynchronously versus synchronously (Wickes et al., 2015).

\section{Methods}

This study explores asynchronous cooperation to investigate the factors underlying the results of prior studies that indicate asynchrony affects the well-established processes of cooperative learning. We gathered quantitative and qualitative data to examine the following research questions.

1. Are there differences in cooperative processes between synchronous and asynchronous modes of cooperative learning?

2. Are there differences in belonging between synchronous and asynchronous modes of cooperative learning?

3. Are there differences in emotion (positive and negative) between synchronous and asynchronous modes of cooperative learning?

4. Are there differences in how students engage in cognitive processes when in synchronous/asynchronous modes of discussion? 


\section{Participants}

We collected data from 52 undergraduate students (62\% female, 91\% Caucasian) in an online teacher education course at a public university in the Midwest. See Table 1 for demographic characteristics.

Table 1.

Participant Demographic Characteristics

\begin{tabular}{ll} 
Students $(N=52)$ & $\%$ Stu \\
\hline & \\
Sex & \\
Male & $38 \%$ \\
Female & $62 \%$ \\
& \\
Race/Ethnicity & \\
White & $90 \%$ \\
Black & $4 \%$ \\
Multi-Racial & $2 \%$ \\
Asian/Pacific Islander & $2 \%$ \\
Unknown & $2 \%$ \\
& \\
Age & \\
$18-19$ & $8 \%$ \\
$20-21$ & $65 \%$ \\
$22-24$ & $27 \%$
\end{tabular}

Year in School

First $\quad 4 \%$

Second $6 \%$

Third $17 \%$

Fourth $67 \%$

$5+\quad 6 \%$

\section{The Course}

The online course examines learning in and out of school settings from a variety of theoretical perspectives. The course is required for all students entering the teacher preparation program and is also taken by students in other programs as an introduction to psychological and other perspectives on learning. The instructor structured the course as eight two-week modules, with materials for independent work as well as an expectation of weekly participation in smallgroup discussions. Students were assigned to three- to four-person home teams for these weekly discussions. Each student worked with the same home team for the first half of the semester, with new teams formed at mid-semester for the remainder of the course. These weekly small-group discussions are the focus of this study. 
The small-group discussions took place in TitanPad (https://titanpad.com), a collaborative writing tool in which users can simultaneously edit a shared document and engage in text-based chat in an adjacent window (see Figure 1). Each person's writing and chat entries show up in a different color, making individual contributions apparent. Group tasks were presented in the TitanPad document; group members discussed with their group members in the chat window and wrote in the shared document in response to a given prompt, such as "Can you think of examples when family or friends have disagreed about what happened during some shared experience in the past? Can you explain these disagreements based on what you've been learning about memory?" The instructor designed the group work around each module's topics, specifically behaviorism, individual cognitive processing (memory, attention, schemas, stereotypes), social learning and cooperative learning, motivation, and learning as development.

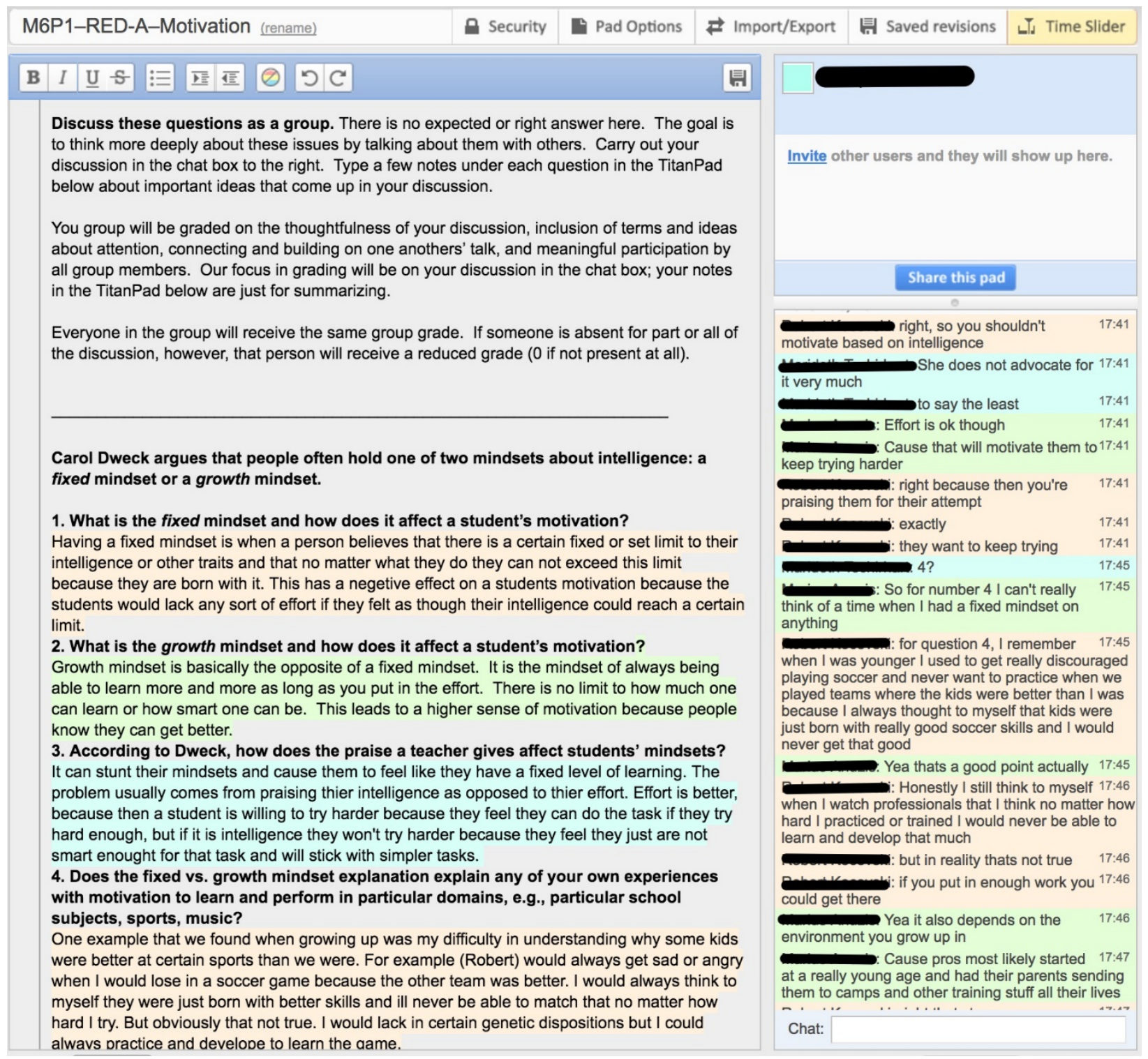

Figure 1. TitanPad example activity. 
Enrolled students were divided randomly into four class sections, with home teams formed within each section. The weekly small-group discussions took place synchronously in two course sections, asynchronously in the other two sections. In the synchronous sections, home teams were directed to agree on a one-hour meeting time between Tuesday and Saturday to hold their smallgroup discussions. Students in the asynchronous sections were directed to participate in their small-group discussion between Tuesday and Saturday each week, with encouragement to participate several times during that time block. Each discussion activity was designed with cooperative goals and instructions to encourage cooperative interaction among group members. Tasks and discussion questions were the same for synchronous and asynchronous sections.

To encourage cooperative behaviors, we provided students with a set of guidelines for participating in group work, which was consistent with prior research indicating computermediated communication rules that enhance trustworthiness and reduce uncertainty (Walther \& Bunz, 2009). The guidelines instructed students to communicate frequently, set deadlines and adhere to them, connect and build on one another's talk, and encourage meaningful participation by all group members. The guidelines included illustrative examples that were specific to the synchronous or asynchronous modality. For instance, the synchronous example for the communicate frequently guideline was, "Use the TitanPad chat feature to hold an engaged conversation with group members. Post in the chat frequently; you don't want to go longer than 5 minutes without posting." The example for asynchronous students was, "Use the TitanPad chat feature to hold an engaged conversation with group members. Check for new messages and post in the chat frequently; try to check in every day, but definitely at least every other day during the posting period (Tuesday through Saturday). When you check TitanPad and there are no new messages, post that you've checked in."

\section{Self-Report Measures}

We administered surveys at two time points: the middle of the semester (after the final discussion with the first home teams) and the end of the semester (after the final discussion with the second home teams). The surveys included items on various motivational and social interdependence constructs. All items included in the analyses were measured on a 5-point Likert scale from 1 (strongly disagree) to 5 (strongly agree). Means and standard deviations for variables used in the analyses are presented in Table 2.

Table 2.

Descriptive Statistics

\begin{tabular}{lcccccc}
\hline & Async T1 & Sync T1 & Async T2 & Sync T2 & Async Total & Sync Total \\
\hline & $M(\mathrm{SD})$ & $M(\mathrm{SD})$ & $M(\mathrm{SD})$ & $M(\mathrm{SD})$ & $M(\mathrm{SD})$ & $M(\mathrm{SD})$ \\
\hline Individualism & $3.59(0.99)$ & $3.24(1.01)$ & $3.65(1.10)$ & $2.99(1.17)$ & $3.59(0.95)$ & $3.15(0.96)$ \\
Cooperative & $3.23(0.94)$ & $3.55(0.66)$ & $3.30(0.93)$ & $3.50(1.05)$ & $3.31(0.89)$ & $3.52(0.73)$ \\
Competitive & $2.58(0.64)$ & $2.62(0.86)$ & $2.69(0.67)$ & $2.57(1.01)$ & $2.65(0.54)$ & $2.61(0.79)$ \\
Belonging & $3.76(0.70)$ & $4.14(0.65)$ & $3.75(0.67)$ & $4.19(0.74)$ & $3.77(0.67)$ & $4.18(0.63)$ \\
Positive Affect & $2.48(1.01)$ & $2.78(1.02)$ & $2.71(1.15)$ & $2.68(1.10)$ & $2.58(0.93)$ & $2.72(0.95)$ \\
Negative Affect & $2.37(1.15)$ & $1.73(0.85)$ & $2.17(1.05)$ & $1.86(1.05)$ & $2.25(0.92)$ & $1.79(0.91)$ \\
\hline
\end{tabular}


Belonging and affect. Student perceptions of belonging and affect were used as measures of motivation. Composite variables were constructed to assess each construct at Time 1 and Time 2. Student perceptions of belonging ( $\alpha=.82 ; .85$ ) consisted of six items ("I felt accepted by my group members") and was adapted from Furrer and Skinner's (2003) measure. Positive affect ( $\alpha=$ $.91 ; .95)$ was constructed from three items ("While working with my group, I generally felt happy"), and negative affect ( $\alpha=.81 ; .85)$ was constructed from three items ("While working with my TitanPad Group, I generally felt anxious") from Linnenbrink’s (2005) measure.

Social interdependence. Perceptions of cooperation, competition, and individualism were assessed using the Social Interdependence Scale (Johnson \& Norem-Hebeisen, 1977). Composite variables were constructed to assess each construct at Time 1 and Time 2. Perceptions of cooperation $(\alpha=.86 ; .91)$ were assessed using a five-item scale ("I learn important things from the other students in my group). Perceptions of competition $(\alpha=.82 ; .81)$ were assessed using a fiveitem scale ("I believe competing with the other student(s) is a good way to work in my group"). Perceptions of individualism $(\alpha=.86 ; .91)$ were assessed using a three-item scale ("I wish we would work by ourselves in this course").

\section{LIWC Measures}

Initially, we examined the chat logs from each cooperative group by counting the number of posts in each group activity. To further examine the chat logs, we used Linguistic Inquiry and Word Count software (Pennebaker, Booth, Boyd, \& Francis, 2015) to examine word count, positive emotion, negative emotion, discrepancy, and certainty. The LIWC software identifies psychological constructs in writing by identifying words within categories, which were developed from psychological measurements. Independent judges rated the word lists to determine the final lists, and then the lists were revised and refined in 1997 and 2007. For each construct, the software determines the percentage of category words within the entire text. Some categories, such as affect, have been evaluated for their correspondence to self-report measures. For example, Tov, $\mathrm{Ng}, \mathrm{Lin}$, and Qiu (2013) found that LIWC-identified frequency coefficients for positive and negative emotion correlated with self-reported positive and negative emotions.

In addition to examining affect in the chat logs, we explore cognitive processes by analyzing two LIWC variables: discrepancy and certainty. The greater use of discrepancy words indicates that the writer is diverting attention away from him or herself (Pennebaker, 2011), and the use of discrepancy verbs suggests a difference between reality and how the writer wants things to be. Discrepancy words are correlated to influencing behavior (Pennebaker, 2011) and high performance (Rodrigo, 2017), and indicates analytical thinking. High use of certainty words can lead to more perceptions of trustworthiness, and they broadcast an individual's willingness to take risks (Moons, Spoor, Kalomiris, \& Rizk, 2013; Watson \& Spence, 2007). Trustworthiness is especially important for cooperation, as they develop reciprocally, with trustworthiness creating more cooperation and more cooperation creating more trustworthiness (Ferrin, Bligh, \& Kohles, 2008). We expect both discrepancy and certainty words to be present in the cooperative groups because trustworthiness affects cooperation and cognitive processing in cooperative groups relies on explaining, summarizing, and integrating ideas from other.

In our study, each chat post in the chat logs varied from one word to 495 words, which could skew the construct ratio for shorter posts. Therefore, we aggregated all of the posts from an individual in a specific conversation and conducted our analysis at the conversation level. The content of the course encouraged the use of specific words that may have influenced the LIWC 
analysis. For example, the discussion about stereotypes may have triggered the use of more negative emotion words (e.g., hurt, worried, annoyed) than the discussion about behaviorism. Although the topics may have affected the LIWC analysis, we assumed that the topics would have the same influence in both the synchronous and asynchronous groups.

\section{Analysis}

The first, second, and third research questions (synchrony and cooperative perceptions, synchrony and belonging, and synchrony and emotion were answered by conducting a repeated measures MANOVA using self-report measures of cooperation, competition, individualism, belonging, positive affect, and negative affect. In addition, we conducted a multiple linear regression to supplement our primary analysis. To answer our fourth research question (synchrony and cognitive processes) and further explore the third research question (synchrony and emotion) we conducted a one-way between-groups MANOVA with the LIWC-coded chat log data for positive emotion, negative emotion, discrepancy, and uncertainty.

\section{Preliminary Self-Report Analysis}

\section{Results}

Means and standard deviations of all variables used in the self-report analysis are presented in Table 2. Overall, students in asynchronous groups reported higher levels of individualism, competition, and negative affect compared to students in the synchronous groups. Students in the synchronous groups reported higher levels of cooperative perceptions, belonging, and positive emotions compared to students in the asynchronous groups.

\section{Self-Report Analysis}

To address the first three research questions (asynchrony's effect on cooperation, belonging, and emotion), a repeated measures MANOVA was conducted to examine whether there were differences in belonging, individualism, and negative affect between groups (synchronous/asynchronous) and within groups (two time points). Five students were dismissed from the final analyses due to incomplete data, leaving 47 students (51\% synchronous). Results are presented in Table 3.

Table 3

Summary of Repeated Measures MANOVA

\begin{tabular}{llllllll}
\hline & & \multicolumn{5}{c}{ ANOVA, $F(1,45)$} \\
\cline { 3 - 7 } Factor & MANOVA, $F(6,40)$ & Ind & Coop & Comp & Bel & Pos Aff & Neg Aff \\
\hline Synchrony & 1.39 & $3.97^{* *}$ & 1.84 & 0.02 & $4.72^{* *}$ & 0.26 & $3.66^{*}$ \\
Time & 0.20 & 0.41 & 0.20 & 0.29 & 0.57 & 0.09 & 0.26 \\
Synchrony x time & 0.74 & 0.55 & 0.89 & 0.53 & 0.20 & 1.28 & 2.37 \\
\hline
\end{tabular}

${ }^{*} \mathrm{p}<.10,{ }^{* *} \mathrm{p}<.05$

The repeated measures MANOVA showed no significant multivariate effect for between subjects (for each construct) across learning mode (regardless of time), $F(6,40)=1.39, p=0.24$. Furthermore, there was no significant multivariate effect for within-subjects across time 
(regardless of learning mode), $F(6,40)=0.20, p=0.98$. There was also no significant multivariate effect across interaction between learning mode and time, $F(6,40)=0.74, p=0.62$.

However, when we examined the univariate results of the study, student perceptions of belonging were higher for students in the synchronous group than the asynchronous group, $F$ $(1,45)=4.72, p=0.04$, partial eta squared $=0.10$; perceptions of individualism were higher for students in the asynchronous group than the synchronous group, $F(1,45)=3.97, p=0.05$, partial eta squared $=0.08$; and negative affect was higher for students in the asynchronous group than in the synchronous group, $F(1,45)=3.66, p=0.06$, partial eta squared $=0.08$. There were no significant differences between synchronous and asynchronous groups when examining positive affect, perceptions of cooperation, or perceptions of competition. Although there were significant differences between online learning mode, there were neither significant effects across time for the constructs measured nor significant interaction between learning mode and time.

\section{Secondary Self-Report Analysis}

Because significant differences were found between synchronous and asynchronous groups for multiple measures, we conducted a linear multiple regression to supplement our primary analysis. Synchrony and social interdependence variables (cooperation, competition, and individualism) were used as predictors to examine the relationship between belonging and negative affect. Composite variables were constructed to represent average levels of belonging, negative affect, cooperation, competition, and individualism across all time points. Correlations for variables included in this analysis are included in Table 4. Results of the multiple regression are included in Table 5.

Table 4

Correlations

\begin{tabular}{lcccccc}
\hline & $\mathbf{1}$ & $\mathbf{2}$ & $\mathbf{3}$ & $\mathbf{4}$ & $\mathbf{5}$ & $\mathbf{6}$ \\
\hline 1. Synchrony & & & & & & \\
2. Belonging & $.30^{*}$ & & & & & \\
3. Negative Affect & -.25 & $-.66^{* *}$ & & & & \\
4. Competition & -.03 & $-.24^{* * *}$ & .26 & & & \\
5. Cooperation & .14 & $.72^{* *}$ & $-.58^{* *}$ & .03 & & \\
6. Individualism & -.23 & $-.47^{* *}$ & $.66^{* *}$ & $.30^{*}$ & $-.64^{* *}$ & \\
${ }^{*} \mathrm{p}<.05,{ }^{* *} \mathrm{p}<.01,{ }^{* * *} \mathrm{p}<.001$ & & & &
\end{tabular}


Table 5

Summary of Multiple Regressions

\begin{tabular}{|c|c|c|c|c|}
\hline & \multicolumn{2}{|c|}{ Belonging } & \multicolumn{2}{|c|}{ Negative Affect } \\
\hline & $\mathrm{B}(\mathrm{SE})$ & $\beta$ & $\mathrm{B}(\mathrm{SE})$ & $\beta$ \\
\hline Intercept & $1.78(0.56)$ & & $1.61(.90)$ & \\
\hline Synchrony & $0.31(0.12)$ & $0.23^{*}$ & $-0.20(0.20)$ & -0.11 \\
\hline Competition & $-0.32(0.10)$ & $-0.32^{* *}$ & $0.20(0.16)$ & 0.15 \\
\hline Cooperation & $0.70(0.10)$ & $0.83^{* * *}$ & $-0.37(0.16)$ & $-0.33^{*}$ \\
\hline Individualism & $0.15(0.09)$ & 0.22 & $0.37(0.14)$ & $0.39^{*}$ \\
\hline $\mathrm{F}(4,46)$ & \multicolumn{2}{|c|}{$20.49^{* * *}$} & \multicolumn{2}{|c|}{$11.94^{* * *}$} \\
\hline $\mathrm{R}^{2}$ & \multicolumn{2}{|c|}{0.64} & \multicolumn{2}{|c|}{0.51} \\
\hline $\operatorname{Adj} \mathrm{R}^{2}$ & \multicolumn{2}{|c|}{0.61} & \multicolumn{2}{|c|}{0.47} \\
\hline
\end{tabular}

For belonging, $61 \%$ of the variation was explained by synchrony, cooperation, competition, and individualism, $F(4,46)=20.49, p<.001$. All independent variables were significant except for individualism. Cooperation $(\beta=.83, p<.001)$ positively predicted belonging whereas competition $(\beta=-.32, p=.002)$ negatively predicted belonging. Synchrony also showed a positive relationship with belonging $(\beta=.23, p=.02)$. For negative affect, $47 \%$ of the variation was explained by the individualism variable, $F(4,46)=11.94, p<.001$. The only significant predictors of negative affect were cooperation $(\beta=-.33, p=.03)$ and individualism $(\beta=.39, p=.01)$.

\section{Preliminary LIWC Analysis}

Students exchanged 4,379 posts over 11 discussions, with students in the synchronous group exchanging most of the posts $(84.9 \%)$. At the conversation level, students in the synchronous and asynchronous conditions posted in different patterns. Synchronous students wrote 218.43 (SD $=159.61)$ words per conversation, with an average of $14.99(S D=15.67)$ words per post. Asynchronous students wrote $108.04(S D=79.71)$ words per conversation with an average of $31.17(S D=28.91)$ words per post. In other words, the synchronous students rapidly exchanged shorter posts. A t-test was used to confirm that there were significant differences for words per conversation $(t(461)=-9.08, p<.001)$ and words per post $(t(4516)=22.06, p<.001)$ between synchronous and asynchronous students. Using Cohen's (1988) guidelines, the magnitude of the differences in the means for words per conversation (mean difference $=-110.38,95 \%$ CI: -134.29 to -86.49 ) was large (eta squared $=.15$ ) and the magnitude of the differences in the means for words per post (mean difference $=16.18,95 \% C I$ : 14.75 to 17.723 ) was moderate (eta squared $=$ $.10)$.

Means and standard deviations of all variables included in the LIWC analysis of chat logs are included in Table 6. Overall, students in the synchronous groups had higher mean values on all variables included in the analysis compared to students in the asynchronous groups. 
Table 6

LIWC Descriptive Statistics

\begin{tabular}{lll}
\hline & \multicolumn{1}{c}{ Async } & \multicolumn{1}{c}{ Sync } \\
\hline & \multicolumn{1}{c}{$M(\mathrm{SD})$} & \multicolumn{1}{c}{$M(\mathrm{SD})$} \\
\hline Tone & $69.21(30.41)$ & $76.92(26.41)$ \\
Affect & $5.69(4.72)$ & $6.36(4.06)$ \\
Positive Emotion & $4.70(4.80)$ & $4.98(3.20)$ \\
Negative Emotion & $0.94(1.58)$ & $1.33(2.66)$ \\
Discrepancy & $1.71(1.93)$ & $2.12(1.85)$ \\
Tentativeness & $3.11(2.83)$ & $3.43(2.18)$ \\
Certainty & $1.59(1.80)$ & $2.37(3.44)$ \\
\hline
\end{tabular}

\section{LIWC Analysis}

To explore the fourth research question (synchrony's effect on cognitive processes) and further examine the third research question (synchrony's effect on emotion), a one-way betweengroups MANOVA was used to investigate differences between synchronous and asynchronous groups on positive emotion, negative emotion, discrepancy, and certainty in discussion posts using the LIWC software. Results are presented in Table 7.

Table 7

LIWC One-way Between-Groups MANOVA

\begin{tabular}{|c|c|c|c|c|c|c|c|c|}
\hline \multirow[b]{2}{*}{ Factor } & \multirow[b]{2}{*}{ MANOVA, $F(7,455)$} & \multicolumn{7}{|c|}{ ANOVA, $F(1,461)$} \\
\hline & & Tone & Affect & $\begin{array}{l}\text { Positive } \\
\text { Emotion }\end{array}$ & $\begin{array}{l}\text { Negative } \\
\text { Emotion }\end{array}$ & Discrepancy & Tentativeness & Certainty \\
\hline Synchrony & $5.71^{* * *}$ & $8.51^{* *}$ & 2.74 & 0.57 & $3.47^{\dagger}$ & $5.50^{*}$ & 1.93 & $8.86^{* *}$ \\
\hline
\end{tabular}

There was a statistically significant difference between synchronous and asynchronous groups on the combined dependent variables, $F(4,458)=5.41, p<0.001$; Pillai's Trace $=0.05$; partial eta squared $=0.05$. When the results for the dependent variables were considered separately, significant results were found between groups for negative emotions $F(1,461)=3.47, p=0.063$, partial eta squared $=0.007$, discrepancy $F(1,461)=5.50, p=0.019$, partial eta squared $=0.012$, and certainty $F(1,461)=8.86, p=0.003$, partial eta squared $=0.019$. No significant results were found between groups for positive emotions. When examining the mean scores, students' in the synchronous groups had higher mean scores on negative emotions, discrepancy, and certainty when compared to students' in the asynchronous groups.

\section{Discussion}

This study explored the effects of synchrony on belonging and affect as outcomes of cooperation. As expected, students communicating asynchronously had higher individualistic perceptions. This finding supports prior research that asynchronous communication interferes with the relationship between cooperative goals and cooperation (Peterson \& Roseth, 2016; Roseth, Saltarelli, \& Glass, 2011; Saltarelli \& Roseth, 2014). Those who collaborated asynchronously also 
had lower perceptions of belonging and higher negative affect. Although these findings might suggest that asynchrony negatively affects the outcomes of cooperative learning, our second analysis revealed a more precise understanding and extends prior research.

In our second analysis of the self-report measures, we investigated the two cooperative outcomes identified as having mean differences (belonging and negative affect) to identify whether asynchrony affected those outcomes beyond its effect on cooperation. We found that asynchrony affects the relationship between cooperative goals and cooperative perceptions, but the relationship between cooperative perceptions and outcomes is mixed. Both synchrony and interdependence perceptions predicted belonging. In the self-report measures, we found that interdependence perceptions (cooperation and individualism) were significant predictors of negative affect, while synchrony was not.

\section{Chat Logs}

Within the chat logs, the LIWC analysis identified words for each category. The results described above indicate that both the synchronous and asynchronous groups were similar in their use of positive emotion words, like agree, better, well, and great. Synchronous groups used more negative emotion words (e.g., sorry, disagree, mistake, bad), discrepancy words (e.g., should, would, could, hoping), and certainty words (e.g., always, never, all, completely). In this section, we provide examples of how students used the words in each of these categories, and those words are indicated by the italicized text.

Pennebaker (2011) describes the LIWC emotion words as a "rough measure of people's emotional state" (location 204). Arguello et al. (2006) found that the use emotions words in online discussions increase the likelihood of getting a reply to a post. Emotion words have been used to measure a person's immersion in an experience or event (Tausczik \& Pennebaker, 2010). In this study, students use positive emotion to express agreement with and encouragement to their group mater. In using negative emotion word, they apologized for poor team behavior and compared their ideas with those of others. In addition, the group discussion about stereotypes elicited negative emotion words.

Students often used positive emotion words to express agreement with their group mates. For example, one student posted, "Hello! :) Okay, sounds good! :) So, I think we can agree the reason why we didn't notice the changing objects in the card trick and monkey business videos are due to use paying close attention to something else." Another student posted, "And I really liked how you connected the concept of selective attention to how we behave in society. Yeah i agree with that!!"

Students used positive emotion words to make supportive and encouraging statements to group members. One student posted, "Casey great example of a TV show that stereotypes.", and another posted:

I also found it very interesting that none of us brought up the same stereotypes. We all discussed something different, but they all stemmed from what society told us to think, mass media, or others in our lives. I also am glad that we came to our own judgment about the stereotypes in our lives. I truly enjoyed reading everyone's post and everyone did a great job!

Many of the negative emotion examples included apologies. For example, variations of "Hi Everyone... Sorry for the delay on joining the group." was common in the synchronous groups. 
Negative emotion words appeared in post that expressed problems with technology, such as "I'm really sorry I'm so confused by this titan pad thing $:$ " and "Tiffany, I made a mistake and erased some of your name and it's showing up in my color. I'm going to erase that and you can put it back if you want."

Few students used negative emotion words when comparing their ideas with those of their group mates. For example, one student said, "I disagree with Jacob because I believed fixed mindset is when people don't think they can change the way they think and learn." Although students rarely used negative emotion words to disagree with each other in practice, they recognized that disagreement was part of cooperative learning, as one student describes, "I feel that working together means that a group of people are focusing on completing a task together. They may be arguing and disagreeing when working together."

The most common use of negative emotion words was in the discussion of specific topics. In the discussion about fixed and growth mindset, students frequently used the words fail and failure. One student explained, "When I was younger I had a fixed mindset and didn't push myself. I also would be completely destroyed by failure. Now that I'm older I have a growth mindset because I look at failure positively."

In particular, the stereotypes discussion involved high percentages of negative emotion words. One student posted:

Yeah i agree, it's not exactly ethical but it definitely taught an important lesson.

There was no physical harm being brought to them. I think the teacher probably could have thought of a better option though to avoid the grey area.

Another student posted, "The teachers words had a huge impact on the students they're so young and those words really hurt their feelings. The brown eyed were hurt and felt bad about themselves because of their eye color." Although the topic of stereotypes should have elicited negative emotion words from both groups, the synchronous students were more likely to use these words. The synchronous students may have been more willing to talk directly about a difficult topic because they could feel assured that they will receive a quick response from their group mates, which would allow them to rectify any misunderstandings. In other words, the synchronous students may have found it less risky to discuss a difficult topic directly.

The use of discrepancy words may be able to encourage cooperation by facilitating explanation and reflection. In the present study, students in the synchronous groups used more discrepancy words than those in the asynchronous group. In analyzing the chat transcripts, we found that students used the discrepancy words to negotiate the logistics of the group work, test out their ideas, and influence the ideas of the group.

Students used discrepancy words to suggest how they could proceed with the group work. For example, a student posted:

Also for the 3 scenarios I think if we wanted to pick A we could discuss the idea that the teacher should respond by praising the students hard work but not how smart they might be to encourage that work to continue. We could then integrate how in the presentation from Amy how she learned that it was beneficial to do that or also use an example from one of the studies in the article about praise. 
In one case, a student used discrepancy words to suggest an approach to make the group more effective by posting, "Hey guys! I was hoping for this week we could start getting discussion going earlier on in the week! I will try to be checking the pad everyday. I think that would make discussion go better!"

Discrepancy words allowed students to test out answers, such as "I think that for that texting and driving question, the individual driving would be using a zoom-lens method of selective attention. Actually, he or she could also be using the spotlight model." Another student posted, "Do we want to do a picnic? I have a decent photo for that too."

More commonly, students used discrepancy words to influence the ideas of the group. For example, a student posted:

For 4 maybe we could say something about how our interests determine whether we have a fixed mindset or a growth mindset about a certain subject. For instance, if I hated math maybe I would be more content with just knowing what I know and not expecting my knowledge to expand. Idk [I don't know] what do you guys think?

Another student posted:

I think people would think of things that they have categorized as belonging in a bedroom, even if they aren't in this picture. I was thinking a busy street. For that I would say people would remember the guy with the yellow backpack.

The LIWC category of certainty includes words that express "authoritativeness" and confidence. Those who are perceived as authoritative are seen as trustworthy, which facilitates cooperation. The primary purposes of students' use of certainty words were to express their confidence in their ideas and to encourage group members.

Students used certainty words to express authoritativeness when explaining their ideas. For example, one student posted, "We all discussed something different, but they all stemmed from what society told us to think, mass media, or others in our lives." Another posted, "Product placement is huge when it comes to grabbing attention. That happens to me all the time in grocery stores! Especially with sale signs." Another explained, "I feel a lot of people believe they have the ability to multitask, especially our generation, but driving already has so many elements that must be focused on." However, students were apt to use certainty words to express a lack of authoritativeness as well. For example, a student posted, "I'm not completely sure on how to expand on my answer." Another admitted, "The card video completely stumped me." Similarly, a student posted, "I never realized or would have thought about passages that way either that or my thought process when looking at the pictures or reading them was in the total wrong direction."

Using certainty words, students posted recognition and encouragement of their group mates. "Hi everyone! I think everyone did a great job with their thoughts about attention and how it is used in real life and not just in magic." Another student posted, "I truly enjoyed reading everyone's post and everyone did a great job!" Using certainty words in this type of post might have contributed to trustworthiness in the group.

When we examine the self-report and chat log results together, a complicated picture emerges. Although there was no difference in positive affect in the self-report measure or the chat $\log$, the results regarding negative affect are mixed. In the self-report measure, asynchronous groups had higher negative affect in the self-report measure, but secondary analysis revealed that cooperation and individualism perceptions predicted negative affect. The analysis of the chat $\operatorname{logs}$ 
indicates that the synchronous students were more likely to use negative emotion words. These differing results suggest that students in the asynchronous groups may refrain from expressing their negative emotions within the discussion. Asynchronous students may perceive the expression of negative emotions as a risk and refrain from it, although this study did not examine this explanation.

In our exploratory LIWC analysis of cognitive processes (discrepancy and certainty), we found that students in the synchronous condition had higher use of discrepancy and certainty words, which indicate analytical thinking (Pennebaker, 2011). This result indicates that students in the synchronous condition expressed more authoritativeness and willingness to take risks. The use of these words may contribute to collaboration by facilitating the discussion of logistics, sharing of ideas, and encourage the group.

\section{Limitations and Implications}

We note two primary limitations to this study. First, we did not control for the level of participation. Although we provided interaction guidelines to encourage equal interactions and the instructional design of the conditions was identical, the asynchronous groups exchanged fewer posts than the synchronous groups, and the lower interaction may have affected the perceptions of interdependence. Second, we designed the tasks with cooperative goal interdependence, although we did not assess whether students clearly understood the cooperative goals. Despite these limitations, the study provides clear evidence of the positive effects of synchronous interaction on cooperation, belonging, and affect.

These findings are important for theory because they indicate that asynchrony affects the empirically established relationship between cooperative goals and cooperative perceptions. The affect and belonging differences we identified suggest that online learning is not a uniform environment, but a varied environment with different behavioral options and communication process that affect cooperation. For practitioners, these results suggest that asynchronous cooperative learning may not work as designed, because the presence of cooperative goals does not predict cooperative outcomes in asynchronous cooperation. This study indicates that further research should investigate whether instructors should require synchronous cooperation in small group work to achieve greater cooperation and belonging or whether there are other ways to structure asynchronous cooperation to achieve these outcomes. Future research should continue to explore ways to induce cooperative perceptions in learning facilitated by asynchronous communication. Our results warrant future research to explore whether students working asynchronously perceive expressing negative emotion as a risk and therefore avoid it. Although we have identified differences in the use of discrepancy and certainty words in synchronous and asynchronous contexts, future research should further explore how students are using cognitive process in synchronous and asynchronous cooperation. 


\section{References}

Arguello, J., Butler, B., Joyce, E., Kraut, R., Ling, K. S., Rosé, C., \& Wang, X. (2006). Talk to me: Foundations for successful individual-group interactions in online communities. In CHI 2006 Proceedings (pp. 959-968). Montreal, Quebec: CHI.

Baumeister, R. F., \& Leary, M. R. (1995). The need to belong: Desire for interpersonal attachments as a fundamental human motivation. Psychological Bulletin, 117, 497-529.

Cherney, M. R., Fetherston, M., \& Johnsen, L. J. (2017). Online course student collaboration literature: A review and critique. Small Group Research, 1-31. https://doi.org/10.1177/1046496417721627

Cohen, J. W. (1988). Statistical power analysis for the behavioral sciences (2nd ed.). Hillsdale, NJ: Lawrence Erlbaum Associates.

Deutsch, M. (1949). A theory of cooperation and competition. Human Relations, 2, 129-152. doi:10.1177/001872674900200204

Deutsch, M. (2012). A theory of cooperation: Competition and beyond. In P. A. M. Van Lange, A. W. Kruglanski, \& E. T. Higgins (Eds.), Handbook of Theories of Social Psychology: Volume 2 (pp. 275-294). London: Sage Publications. https://doi.org/10.4135/9781446249222.n40

Ferrin, D. L., Bligh, M. C., \& Kohles, J. C. (2008). It takes two to tango: An interdependence analysis of the spiraling of perceived trustworthiness and cooperation in interpersonal and intergroup relationships. Organizational Behavior and Human Decision Processes, 107, 161-178. https://doi.org/10.1016/j.obhdp.2008.02.012

Furrer, C., \& Skinner, E. (2003). Sense of relatedness as a factor in children's academic engagement and performance. Journal of Educational Psychology, 95, 148-162. doi:10.1037/0022-0663.95.1.148

Jeong, H., \& Hmelo-Silver, C. E. (2012). Technology supports in CSCL. In J. van Aalst, K. Thompson, M. J. Jacobson, \& P. Reinmann (Eds.), The future of learning: Proceedings of the 10th International Conference of the Learning Sciences (ICLS 2012)_Volume 1, Full papers (pp. 339-346). Sydney, Australia: Society of the Learning Sciences.

Jeong, H., \& Hmelo-Silver, C. E. (2016). Seven affordances of computer-supported collaborative learning: How to support collaborative learning? How can technologies help?

Educational Psychologist, 51, 247-265. https://doi.org/10.1080/00461520.2016.1158654

Johnson, D. W., \& Johnson, R. T. (1989). Cooperation and competition: Theory and research. Edina, MN: Interaction Book Company.

Johnson, D. W., \& Johnson, R. T. (2005). New developments in social interdependence theory. Genetic, Social, and General Psychology Monographs, 131, 285-358. https://doi.org/10.3200/MONO.131.4.285-358

Johnson, D. W., \& Norem-Hebeisen, A. (1977). Attitudes toward interdependence among persons and psychological health. Psychological Reports, 40, 843-850. 
Linnenbrink, E. A. (2005). The dilemma of performance-approach goals: The use of multiple goal contexts to promote students' motivation and learning. Journal of Educational Psychology, 97, 197-213. https://doi.org/10.1037/0022-0663.97.2.197

Meyer, K. A., \& Jones, S. J. (2012). Do students experience "social intelligence," laughter, and other emotions online? Journal of Asynchronous Learning Network, 16(4), 99-111.

Moons, W. G., Spoor, J. R., Kalomiris, A. E., \& Rizk, M. K. (2013). Certainty broadcasts risk preferences: Verbal and nonverbal cues to risk-taking. Journal of Nonverbal Behavior, 37, 79-89. https://doi.org/10.1007/s10919-013-0146-0

Pekrun, R., Linnenbrink-Garcia, L. (2012). Academic emotions and student engagement. In S. L. Christenson et al. (Eds.), Handbook of Research on Student Engagement (pp. 259-282). Springer. https://doi.org/10.1007/978-1-4614-2018-7_12

Pennebaker, J. W. (2011). The secret life of pronouns: What our words say about us [E-reader version]. New York: Bloomsbury Press.

Pennebaker, J.W., Booth, R.J., Boyd,R.L., \& Francis, M.E. (2015). Linguistic Inquiry and Word Count: LIWC2015. Austin, TX: Pennebaker Conglomerates (www.LIWC.net).

Peterson \& Roseth, C. J. (2016). Effects of four CSCL strategies for enhancing online discussion forums: Social interdependence, summarizing, scripts, and synchronicity. International Journal of Educational Research, 76, 147-161. https://doi.org/10.1016/j.ijer.2015.04.009

Rodrigo, M. M. T. (2017). Exploratory analysis of discourses between students engaged in a debugging Task. In W. Chen (Ed.), Proceedings for the 25th International Conference on Computers in Education. New Zealand: Asia-Pacific Society for Computers in Education. Retrieved from http://icce2017.canterbury.ac.nz/sites/default/files/proceedings/main/C2/Exploratory Analysis of Discourses between Students Engaged in a Debugging Task.pdf

Roseth, C. J., Saltarelli, A. J., \& Glass, C. R. (2011). Effects of face-to-face and computermediated constructive controversy on social interdependence, motivation, and achievement. Journal of Educational Psychology, 103, 804-820. https://doi.org/10.1037/a0024213

Saltarelli, A. J., \& Roseth, C. J. (2014). Effects of synchronicity and belongingness on face-toface and computer-mediated constructive controversy. Journal of Educational Psychology, 106, 946-960.

Schunk, D. H., Meece, J. L., \& Pintrich, P. R. (2014). Motivation in education: Theory, research, and applications (4th ed.). Upper Saddle River, NJ: Pearson.

Stahl, G., Koschmann, T., \& Suthers, D. (2014). Computer-supported collaborative learning. In The Cambridge Handbook of Learning Sciences (pp. 479-500).

Tausczik, Y. R., \& Pennebaker, J. W. (2010). The psychological meaning of words: LIWC and computerized text analysis methods. Journal of Language and Social Psychology, 29(1), 24-54. https://doi.org/10.1177/0261927X09351676

Tov, W., Ng, K. L., Lin, H., \& Qiu, L. (2013). Detecting well-being via computerized content analysis of brief diary entries. Psychological Assessment, 25, 1069-1078. https://doi.org/10.1037/a0033007 
Walther, J. B., \& Bunz, U. (2005). The rules of virtual groups: Trust, liking, and performance in computer-mediated communication. Journal of Communication, 55, 828-846.

Waters, J. (2012). Thought-leaders in asynchronous online learning environments. Journal of Asynchronous Learning Networks, 16(1), 19-34.

Watson, L., \& Spence, M. T. (2007). Causes and consequences of emotions on consumer behaviour: A review and integrative cognitive appraisal theory. European Journal of Marketing, 41(5-6), 487-511. https://doi.org/10.1108/03090560710737570

Wicks, D., Craft, B. B., Lee, D. D., Lumpe, A., Henrikson, R., Baliram, N., ... Wicks, K. (2015). An evaluation of low versus high collaboration in online learning. Online Learning, 19(4), 59-80. Retrieved from https://olj.onlinelearningconsortium.org/

Worchel, S., Axsom, D., Ferris, F., Samaha, G., \& Schweizer, S. (1978). Determinants of the effect of intergroup cooperation on intergroup attraction. Journal of Conflict Resolution, 22, 429-439. https://doi.org/10.1177/002200277802200304

Zschocke, K., Wosnitza, M., \& Bürger, K. (2015). Emotions in group work: insights from an appraisal-oriented perspective. European Journal of Psychology of Education, 31, 359384. https://doi.org/10.1007/s10212-015-02 